\title{
Dificuldades na abordagem da pílula contraceptiva de emergência por docentes de Biologia do Ensino Médio do município de Campos dos Goytacazes/RJ
}

\author{
Difficulties in approaching of emergency contraception pill by Biology High School teachers from \\ the municipality of Campos dos Goytacazes/RJ \\ Dificultades en el abordaje de la píldora anticonceptiva de emergencia por docentes de Biología de \\ la Escuela Secundaria del municipio de Campos dos Goytacazes / RJ
}

Isabella Mota Raphael de Lima Arêas

ORCID: https://orcid.org/0000-0001-6374-0901 Instituto Federal de Educação, Ciência e Tecnologia Fluminense, Brasil E-mail: isabellamrlima@gmail.com

Suany Rocha de Almeida ORCID: https://orcid.org/0000-0002-2508-3311 Instituto Federal de Educação, Ciência e Tecnologia Fluminense, Brasil E-mail: suanyalmeida100@hotmail.com Geísa Fonseca de Gonçalves

ORCID: https://orcid.org/0000-0002-3686-2951 Instituto Federal de Educação, Ciência e Tecnologia Fluminense, Brasil E-mail: geisafgoncalves@gmail.com

\begin{abstract}
Resumo
A Anticoncepção de Emergência (AE), também conhecida por "pílula do dia seguinte", é um método anticonceptivo muito utilizado pelas adolescentes, mas pouco ou não abordado na escola. Assim, este trabalho teve como objetivo investigar a abordagem da pílula contraceptiva de emergência nas aulas de professores de Biologia atuantes no Ensino Médio de escolas públicas e particulares do município de Campos dos Goytacazes/RJ, em relação à anticoncepção de emergência e seus efeitos, sua presença nos livros didáticos, a relevância da temática e as dificuldades na abordagem dentro das aulas. Também foi investigado o uso de metodologias ativas de aprendizagem pelos professores. Os dados qualitativos da pesquisa foram coletados através de questionário online. Os resultados da pesquisa mostraram a incipiente abordagem do tema "pílula contraceptiva de emergência" nas escolas tanto pelos professores quanto pelos materiais didáticos e as dificuldades encontradas pelos docentes em relação, principalmente, aos mitos dos efeitos da $\mathrm{AE}$ e aos tabus na aborgadem do tema. Além disso, muitos professores consideraram, erroneamente, a AE como abortiva. Portanto, é necessário aprofundar esse tema nos materiais didáticos e entre os professores para ampliar o conhecimento dos alunos e da sociedade e, assim, reduzir os preconceitos e mitos sobre a anticoncepção de emergência.
\end{abstract}

Palavras-chave: Educação sexual; Pílula contraceptiva de emergência; Ensino de Biologia; Ensino.

\begin{abstract}
The Emergency Contraception, also known as "morning-after pill" is a birth control method widely used by teenagers, however its mention is insufficient or non-existent in the school. Therefore, this study aimed to investigate the emergency contraception pill approach inside classes of Biology teachers working at public and private schools in Campos dos Goytacazes/RJ with regard to the emergency contraception and its efects, the presence inside textbooks, the theme relevance and the difficulty in approaching in classes. It was also investigated the use of active learning methodologies by the teachers. Qualitative research data were collected throughout the online questionnaire. The study's results reveal the underdeveloped approach of the topic "emergency contraception pill" in the schools by both teachers and teaching materials and the difficulties encountered by teachers in relation, mainly, to the myths of the effects of AE and to taboos on the subject. Futhermore, many teachers mistakenly considered EC to be abortive. Therefore, it is necessary to deepen this theme in didactic materials and among teachers to increase the knowledge of students and society and, thus, reduce prejudices and myths about emergency contraception.
\end{abstract}

Keywords: Sexual education; Emergency contraception; Biology teaching; Teaching.

\section{Resumen}

La Anticoncepción de Emergencia (AE), también conocida por "píldora del día siguiente", es un método anticonceptivo muy utilizado por las adolescentes, sin embargo, se lo aborda poco o nada en la escuela. Por 
consiguiente, este trabajo tuvo como objetivo investigar el abordaje de la píldora anticonceptiva de emergencia en las clases de profesores de Biología que actúan en la Secundaria de escuelas públicas y privadas del municipio de Campos dos Goytacazes / RJ, con relación a la anticoncepción de emergencia y sus efectos, su presencia en libros didácticos, la relevancia del tema y las dificultades de abordaje dentro de las clases. Se investigó también el uso de metodologías activas de aprendizaje por parte de los profesores. Los datos cualitativos de la investigación fueron recogidos a través de cuestionario en línea. Los resultados de la investigación mostraron el abordaje incipiente del tema de la "píldora anticonceptiva de emergencia" en las escuelas por los profesores y por el método de enseñanza y las dificuldades encontradas por los docentes en relación, sobretodo, a los mitos acerca de los efectos de la AE y a los tabús que existen cuando se aborda el tema. Además, muchos profesores consideraron erróneamente que la AE era abortiva. Por lo tanto, es necesario profundizar el tema en el material didáctico y entre los profesores para ampliación de conocimiento de los alumnos y de la sociedad, buscando así, reducir los prejuicios y mitos acerca de la anticoncepción de emergencia.

Palabras clave: Educación sexual; Píldora anticonceptiva de emergencia; Enseñanza de Biología; Enseñanza.

\section{Introdução}

A vida sexual dos adolescentes em idade escolar tem iniciado cada vez mais cedo. De acordo com a Pesquisa Nacional de Demografia e Saúde da Mulher e da Criança (PNDS) realizada em 2006, até aos 15 anos, 33\% das meninas pesquisadas já haviam tido relações sexuais e os meninos iniciam a vida sexual com, em média, 16 anos (Brasil, 2010). Em pesquisas mais recentes, pode-se constatar uma diminuição na idade de iniciação. Segundo Serra (2017), cerca de 53\% do quantitativo de adolescentes analisado já tiveram a primeira relação sexual e dizem possuir vida sexual ativa, tendo sido a idade média da primeira relação sexual entre os 12 e 15 anos (Serra, 2017).

Outros resultados da PNDS de 2006 mostram que a fecundidade brasileira sofreu nos últimos anos um processo de rejuvenescimento. A fecundidade das mulheres de 15 a 24 anos representa $53 \%$ da fecundidade total da população feminina. A idade mediana ao ter o primeiro filho diminuiu de 22,4 anos em 1996, para 21 anos em 2006 (Brasil, 2010).

Parte deste rejuvenescimento é devido ao aumento da fecundidade entre adolescentes entre 15 e 19 anos. Uma análise exploratória preliminar dos dados da PNDS 2006 revela que 23,2\% das adolescentes brasileiras de 15-19 anos já iniciaram sua vida reprodutiva - 16,2\% são mães; 5,5\% encontravam-se grávidas pela primeira vez na época da entrevista e 1,5\% haviam vivenciado uma gravidez sem que tenha resultado em filho nascido vivo. Ou seja, em 2006 havia mais adolescentes exercendo ou em vias de exercer papéis sociais próprios da maternidade.

Na pesquisa de Vonk et al. (2013) foram entrevistados 200 adolescentes escolares, sendo 127 do sexo feminino e 73 do sexo masculino, com média de idade de 16,3 para as mulheres e 16,5 para os homens. A pesquisadora pode constatar que os métodos de prevenção mais usados na primeira relação foram preservativos masculinos $(72,6 \%)$, coito interrompido $(8,1 \%) \mathrm{e}$ pílula anticoncepcional $(8,1 \%)$. Apesar do método de contracepção de emergência não estar entre os mais utilizados, segundo a PNDS de 2006, cerca de 12\% das mulheres brasileiras de 15 a 49 anos, sexualmente ativas, que já haviam utilizado um método contraceptivo moderno alguma vez na vida, afirmam ter usado a contracepção de emergência (Brasil, 2010). A PNDS 2006 aponta que o método passou a ocupar o quinto lugar entre os métodos contraceptivos modernos usados por todas as mulheres e é o terceiro dentre os métodos modernos usados por mulheres não unidas e ativas sexualmente (últimos 12 meses). O uso é maior entre as mais jovens, correspondendo a 10,4\% entre adolescentes de 15 a 19 anos que já utilizaram algum método moderno alguma vez na vida; 18,5\% entre jovens de 20 a 24 anos e 16,9\% entre jovens de 25 a 29 anos.

Diante desse cenário, há necessidade de se começar a trabalhar com educação sexual antes mesmo da menarca surgir. A responsabilidade por tratar deste assunto, deve ser da escola e da família em conjunto. Entretanto, ainda nos dias de hoje, em muitas famílias brasileiras, há uma grande barreira quando o assunto é falar sobre sexo. Os pais, em muitos casos, não possuem informação necessária para instruir os seus filhos ou não deixam claro quais os valores da família para eles. Outros sequer conseguem estabelecer um diálogo com os mesmos.

$\mathrm{Na}$ escola ocorrem, cotidianamente, cenas, eventos, gestos, palavras, conversas, referentes à sexualidade em todos os 
níveis educativos. É necessário que haja espaço para que este tema seja questionado, discutido, apropriado e vivenciado de forma única por cada sujeito. A escola deve ofertar esse espaço em que se possa esclarecer e desmistificar tabus que envolvem esse tema. Ao informar e debater esses preconceitos e as dificuldades que ainda são muito grandes no campo da sexualidade, se desconstroem algumas crenças erradas e atitudes que existem na sociedade, levando ao aprimoramento destas concepções.

Entretanto, a educação sexual no Brasil ainda é um processo educativo, no qual os conhecimentos e experiências que são referentes a esse tema, acabam sendo transmitidos de maneira formal. Sabe-se que discutir essa temática dentro do contexto escolar gera um pouco de receio, por esse motivo, as práticas escolares são mais ensinadas através das questões técnicas como assuntos biológicos ou reprodutivos. Porém, sabe-se que a conversa realizada de maneira informal é ainda a mais adequada, através de debates ou diálogos, onde os jovens poderiam expor seus sentimentos de dúvidas ou ansiedades. Um estudo desenvolvido por Viçosa e colaboradores em uma escola pública municipal do Rio Grande do Sul, com 110 discentes do $5^{\circ}$ ao $9^{\circ}$ ano do Ensino Fundamental mostrou que os saberes citados pelos estudantes sobre Educação Sexual estavam mais relacionados à questões biológicas, sem abranger as relações de gênero, relações interpessoais, os sentidos do corpo e a autoestima (Viçosa, et.al., 2020)

É primordial que se reconheça a importância do assunto e a necessidade de existir no âmbito escolar um espaço formal para debater a respeito da sexualidade, em que os alunos tenham oportunidade de expor suas questões dentro das instituições de ensino. De acordo com os Parâmetros Curriculares Nacionais (PCN), a Orientação Sexual na escola deve ser entendida como um processo de intervenção pedagógica que tem como objetivo transmitir informações e problematizar questões relacionadas à sexualidade, incluindo posturas, crenças, tabus e valores a ela associados. Tal intervenção ocorre em âmbito coletivo, enfocando as dimensões sociológica, psicológica e fisiológica da sexualidade (Brasil, 1998).

A transversalidade proposta a partir dos PCN recomenda o professor como principal executor, aquele que ensina, além dos conteúdos programáticos que recebeu em sua formação acadêmica, temas transversais que podem fugir da sua especificidade. Por isso, na maioria das vezes, essa execução fica por conta do professor de Ciências Naturais e ou Biologia que está mais familiarizado com estas questões. Entretanto, muitas vezes, a qualidade da formação profissional desse educador não garante que os conhecimentos, habilidades e atitudes frente ao tema sexualidade o capacitem para tanto. Como a sexualidade é uma temática extremamente associada aos preconceitos, é pouco estudada. Para que o educador venha a trabalhar com este tema em sala de aula, é importante que amplie seus conhecimentos acerca do assunto, para que possa auxiliar os alunos que não possuem informações adequadas, respondendo e esclarecendo suas dúvidas, a fim de contribuir com uma melhora na qualidade de vida dos alunos.

Segundo Silva \& Neto (2006), muitos educadores possuem dificuldades em orientar seus alunos, seja por razões pessoais, seja pela falta de informações específicas voltadas para a área da sexualidade e até mesmo por falta de orientação e de recursos metodológicos que os ajudem a compreender e realizar uma orientação adequada. As próprias instituições de ensino não favorecem uma formação continuada para que os professores possam ampliar seus conhecimentos sobre o assunto abordado.

Além disso, o educador deve desenvolver algumas habilidades que favoreçam a interação e a confiança do educando. Deve desenvolver uma escuta ativa, se dispor a dialogar, estar preparado diante das perguntas e manter uma postura investigativa e de disponibilidade, buscando entender o que realmente o aluno quer saber com aquilo que perguntou. A fim de que tenha mais elementos para satisfazer suas dúvidas, o docente deve procurar responder exatamente aquilo que foi perguntado de um modo que possa ser compreensivo para o aluno, evitando respostas fantasiosas e evasivas.

Uma abordagem temática consciente e respeitosa resultará na formação de futuros adultos psicologicamente mais saudáveis, exercendo a sua sexualidade de forma segura e responsável. Além disso, pode prevenir questões como gravidez precoce e infecções sexualmente transmissíveis (IST), que ocorrem, muitas vezes, por falta de informações. Frequentemente, 
essas doenças são tratadas de formas inadequadas, acarretando problemas de saúde graves no futuro. No que diz respeito aos prejuízos decorrentes da desinformação, as IST podem deixar sequelas, curáveis ou não, como infertilidade, gravidez ectópica, câncer genital, doença hepática crônica, entre outras. (Almeida et al. 2017.)

Outras situações de risco que podem ser causadas pela falta de informação sobre este assunto estão: experiências frustrantes, iniciação de sexo precoce ou masturbação excessiva, além de preconceitos envolvendo o machismo ou a homofobia.

Assim, torna-se essencial desmistificar conceitos equivocados e orientar os adolescentes para que exerçam sua sexualidade com segurança, tranquilidade e plenitude, contribuindo, assim, para uma prática sexual saudável.

A abordagem dessa temática através de metodologias de Aprendizagem Ativa tem se mostrado eficiente (Alves et.al., 2016; Leite \& Rotta, 2013). Aprendizagem ativa é um termo técnico para um conjunto de práticas pedagógicas que abordam a questão da aprendizagem pelos alunos sob uma perspectiva diferente das técnicas clássicas de aprendizagem, tais como aulas discursivas, onde espera-se que o professor "ensine" e o aluno "aprenda". Na aprendizagem ativa, entende-se que o aluno não deve ser meramente um "recebedor" de informações, mas deve se engajar de maneira ativa na aquisição do conhecimento, focando seus objetivos e indo atrás do conhecimento de maneira pró-ativa. Pra que isso funcione, é necessária uma mudança filosófica na postura do professor em sala de aula. Ao invés de pré-organizar os temas importantes e expô-los de maneira metódica e coerente aos alunos, como no ensino tradicional, deve-se focar nos objetivos de aprendizagem que se deseja para eles. Como professores, devemos nos perguntar quais são os itens de aprendizagem que queremos que nossos alunos tenham, e focar na elaboração de perguntas, tarefas, exercícios, projetos ou desafios, que motivem os alunos a correrem atrás do conhecimento necessário para atingir esses objetivos. No passado, como as fontes de informação eram escassas, era mais difícil utilizar a aprendizagem ativa, pois era necessário que a instituição contasse com uma boa biblioteca, onde os alunos poderiam buscar o conhecimento necessário. Hoje em dia, com a Internet, ficou muito mais fácil a aplicação de estratégias de aprendizagem ativa (Gudwin, 2020).

Diante disso, o objetivo geral deste trabalho foi investigar, por meio de um questionário online, direcionado a professores atuantes na rede pública e privada de ensino do município de Campos dos Goytacazes, que lecionam a matéria de Biologia em turmas de Ensino Médio, a abordagem da contracepção de emergência na escola. A hipótese é que os professores abordam o tema superficialmente ou não o abordam em suas aulas.

\subsection{Pílula Contraceptiva de Emergência (Pílula do dia seguinte)}

A Anticoncepção de Emergência (AE) é um método contraceptivo que pode evitar a gravidez após a relação sexual. O método, também conhecido como "pílula do dia seguinte", é recomendado pelo Ministério da Saúde apenas em situações de emergência. É indicado em casos de falha no método de uso rotineiro, como por exemplo, rompimento ou retenção do preservativo, deslocamento do diafragma, esquecimento do anticonceptivo oral, atraso na data do injetável mensal, cálculo incorreto do período fértil e em violência sexual. Não deve ser usado de forma rotineira (Brasil, 2005; Melo et. al, 1997).

A AE é uma medicação hormonal, que contém alta dose de levonorgestrel - um tipo de progesterona sintética - ou uma combinação de levonorgestrel e etinil-estradiol - principal estrógeno endógeno. Existem dois tipos de pílula do dia seguinte: as compostas de uma dose alta de progesterona e as formadas pela associação de estrogênio e levonorgestrel. O anticoncepcional emergencial é vendido nas farmácias sem necessidade de receita e tem suas apresentações - embalagens com um comprimido de $1500 \mathrm{mcg}$ ou com dois comprimidos de $750 \mathrm{mcg}$ cada, que são tomadas em duas doses com um intervalo de 12 horas entre elas, sendo que a primeira dose deve ser ingerida no máximo até 72 horas após a relação sexual, assim como o de dose única. Estudos realizados pela Organização Mundial da Saúde demonstram que a dose única é tão eficaz e segura quanto a dose fracionada. Uma das vantagens de se usar a pílula de dose única é a facilidade de administração e o menor risco 
de esquecimento, porém, a dose única pode aumentar o risco de ocorrência de efeitos indesejáveis (efeitos colaterais) como dores de cabeça, náuseas e irregularidades na menstruação. (Brasil, 2012).

A única contraindicação absoluta para a AE é a gravidez confirmada. Excetuando-se esta condição, todas as mulheres podem usar o método com segurança, mesmo aquelas que, habitualmente, tenham contraindicações ao uso de anticoncepcionais hormonais combinados. (Brasil, 2005).

A eficácia do método vai variar de forma importante em função do tempo entre a relação sexual e a sua administração. Se a pílula for ingerida em até $24 \mathrm{~h}$ após a relação, ela vai apresentar uma taxa de falha de apenas $0,4 \%$. O uso deste método pode ser utilizado com eficácia até três dias após o ato sexual, tendo maior eficácia quanto mais rápido for ingerida. Portanto, deve ser ingerida em até $72 \mathrm{~h}$ após a relação sexual (Brasil, 2005).

Segundo Alves e Lopes, (2008), a pílula do dia seguinte pode desregular a taxa hormonal, provocando alteração no ciclo menstrual, mas quando usado no tempo certo e quantidade certa o único efeito que pode causar é um adiantamento da menstruação em alguns dias. (Portela, 2015)

O principal mecanismo de ação documentado para os regimes de Levonorgestrel (LNG), hormônios combinados e acetato de ulipristal (UPA) é a interferência no processo de ovulação. Se tomado antes do pico pré-ovulatório de hormônio luteinizante (LH), o LNG tem poder de inibir que ocorra o pico de LH, impedindo o desenvolvimento folicular e a maturação e/ou liberação do ovócito. Tem sido observado que o acetato de ulipristal é mais eficaz na prevenção da ovulação, porque pode atuar ainda que o pico de LH já tenha se iniciado, atrasando a ruptura do folículo em pelo menos 5 dias. Nenhum deles impede a ruptura folicular se são tomados no momento de pico do LH. Estes regimes não impedem a implantação de um óvulo fecundado no útero, como observado em vários estudos de acordo com o Consorcio Latinoamericano de Anticoncepción de Emergencia (CLAE) e a Federación Latinoamericana de Sociedades de Obstetricia Y Ginecología (FLASOG) (2015). Dois deles examinaram o efeito das AEs de LNG que determinam o dia do ciclo em que foram administradas por meio de análises hormonais, outros estudos basearam o dia de ciclo pelo resultado relatado pelas próprias mulheres. Nestes estudos, não ocorreram gravidez em mulheres que usaram as AEs antes da ovulação, enquanto houve gravidez em mulheres que as tomaram no dia da ovulação ou após esta já ter ocorrido. Isso mostra que as AEs não impediram a implantação. Outro estudo mostrou que o LNG não impediu que embriões humanos se aderissem à cultura de células do endométrio (in vitro). Estudos realizados em animais demonstraram que o uso das AEs de LNG não impediram a implantação do óvulo fecundado no endométrio. Outros mecanismos de ação das AEs têm sido descritos, como o espessamento do muco cervical, que provoca a retenção dos espermatozoides no colo do útero e as alterações no transporte dos espermatozoides ou ovócito nas trompas. O regime de LNG não tem efeito algum sobre uma gravidez em curso e não aumenta as taxas de aborto espontâneo, se tomado após a implantação. Os dados preliminares de uso de AE a base de ulipristal (UPA) também não mostram efeito sobre a gravidez em curso.

A pílula do dia seguinte chega a ter dez vezes mais hormônios que a convencional. Logo, abusar dela seria um grande risco a saúde, devido aos graves danos que a mesma pode causar no organismo feminino, como os efeitos colaterais que envolvem além de náuseas e vômitos, efeitos tromboembólicos e outras reações adversas como tensão mamária, hemorragia vaginal, fadiga, cefaleias, vertigens, astenia e dores na região baixa do ventre (Braga, 2016).

Além disso, o uso repetitivo ou frequente da AE compromete sua eficácia, que será sempre menor do que aquela obtida com o uso regular do método anticonceptivo de rotina. (Brasil, 2005).

O comportamento contraceptivo na juventude, atualmente, vem apresentando uma dinâmica própria, pois muitas vezes fazem uso desse método de emergência sem conhecimento. Após uma relação sexual não protegida, muitas meninas acabam utilizando a pílula do dia seguinte como forma de prevenir uma gravidez indesejada. Em uma análise, foi demonstrado que os jovens estão usando as pílulas de forma contínua, indevida e indiscriminada, após pesquisa com 136 pacientes de 11 a 
20 anos. Do total pesquisado, $28 \%$ das jovens com vida sexual ativa já havia usado esta pílula e 33\% disseram que não usam outro método, por exemplo, a camisinha, na certeza de que a pílula evita a gravidez. (Nascimento \& Soares, 2015)

Entre as razões para o alto índice de gravidez e IST na adolescência, estão a não utilização de métodos contraceptivos. Os principais motivos que levam os jovens a não usar métodos contraceptivos são a falta de informação sobre os métodos, a não utilização de forma adequada, a falta de diálogo com o parceiro, a própria negação do adolescente quanto à possibilidade de engravidar, os encontros casuais e o ato de assumir sua vida sexual ativa. O desconhecimento ou a inadequação do conhecimento sobre as possibilidades contraceptivas

Os adolescentes também alegam como motivo para não usar o preservativo o fato de estarem em um relacionamento sério, ou seja, terem só um parceiro. Outro motivo que se destaca é não usar preservativo por conhecer o parceiro por muito tempo, atitude de extrema vulnerabilidade. É fundamental que as ações de orientação e prevenção não sejam destinadas apenas para as meninas, mas que envolvam também os meninos nessa responsabilidade conjunta relativa à contracepção. (Silva, et al, 2015)

E apesar de algumas adolescentes terem acesso aos métodos contraceptivos, principalmente à camisinha e pílulas, talvez não tenham a concepção real do benefício e da importância do uso destes. (Silva, et al, 2015)

A inadequação de métodos contraceptivos pelos adolescentes traz consequências danosas não só para eles, como também para toda a sociedade.

Portanto, é de suma importância a necessidade da abordagem desses temas de forma que haja uma aprendizagem significativa que ajude aos adolescentes a tomar decisões responsáveis.

\section{Metodologia}

A pesquisa apresentou perfil qualitativo interpretativo, objetivando observar e interpretar a realidade estudada, buscando explicações alternativas, que possam gerar comparabilidade e exemplaridade (Moreira, 2003). Uma pesquisa de caráter qualitativo se preocupa com o aprofundamento da compreensão de um grupo e seus métodos buscam significados (Gerhardt \& Silveira, 2009).

Como instrumento para coleta de dados, foi utilizado um questionário online estruturado com a finalidade de investigar a presença do tema "Pílula Contraceptiva de Emergência" pela visão de professores atuantes no Ensino Médio que lecionam em escolas públicas e privadas no município de Campos dos Goytacazes. Foram feitas perguntas relacionadas à anticoncepção de emergência e seus efeitos, sua presença nos livros didáticos, a relevância da temática e as dificuldades na abordagem dentro das aulas. Também foi investigado o uso de metodologias ativas de aprendizagem pelos professores. O link do questionário foi disponibilizado através de redes sociais.

Os dados obtidos foram analisados de forma descritiva, sendo apresentados em forma de tabelas e gráficos e interpretados seguindo um processo indutivo (Pereira, et al., 2018).

\section{Resultados e Discussão}

Responderam ao questionário 14 professores, metade que lecionava em instituições de ensino da rede pública e outra metade em instituições privadas. Além disso, metade dos professores envolvidos na pesquisa atuava em todas as séries do Ensino Médio (Gráfico 1). Geralmente, o conteúdo Reprodução Humana, no qual deveriam estar inseridos os métodos contraceptivos, inclusive a "pílula contraceptiva de emergência", é ministrado na primeira ou segunda série do Ensino Médio, de acordo com cada bibliografia utilizada. 
Gráfico 1 - Séries de atuação dos professores participantes da pesquisa.
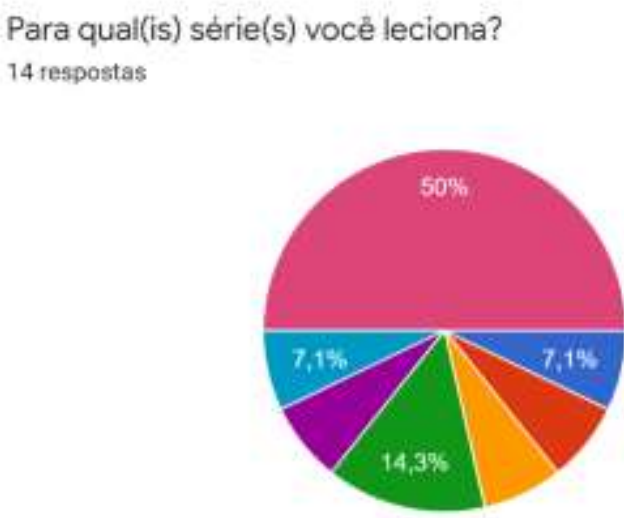

Somente $1^{*}$ Série do Ensino Médio

Somente $2^{4}$ Série do Ensino Médio Somente $3^{a}$ Série do Ensino Médio

Somente $1^{x} \mathrm{e} 2^{*}$ Série do Ensino Médio

Somente $1^{a}$ e $3^{a}$ Serie do Ensino Médio

Somente $2^{\circ}$ e $3^{\circ}$ Série do Ensino Médio

Todas as séries do Ensino Médio

Fonte: Autores.

Entre os professores participantes da pesquisa, pôde-se observar uma pequena parcela da grande diversidade de sistemas de ensino e livros didáticos utilizados dentro das escolas brasileiras (Gráfico 2). 3 utilizavam o Sistema de Ensino Bernoulli, 2 utilizavam o Sistema de Ensino COC, 2 utilizavam o livro Biologia, de José Mariano Amabis e Gilberto Rodrigues Martho, da Editora Moderna e 2 utilizavam o livro Biologia - Unidade e Diversidade, de José Arnaldo Favaretto, da Editora FTD. Outros 3 professores, utilizavam, cada um, sistemas de ensino ou livros didáticos diferentes: Anglo Sistema de Ensino, pH Sistema de Ensino o livro Ciências, Vida e Universo, de Leandro Godoy, da Editora FTD. Uma professora citou que utilizava livro conforme a PNLD (Programa Nacional do Livro Didático, do Ministério da Educação) e outra relatou que ela mesma elabora suas apostilas.

Gráfico 2 - Livros didáticos utilizados pelos professores.

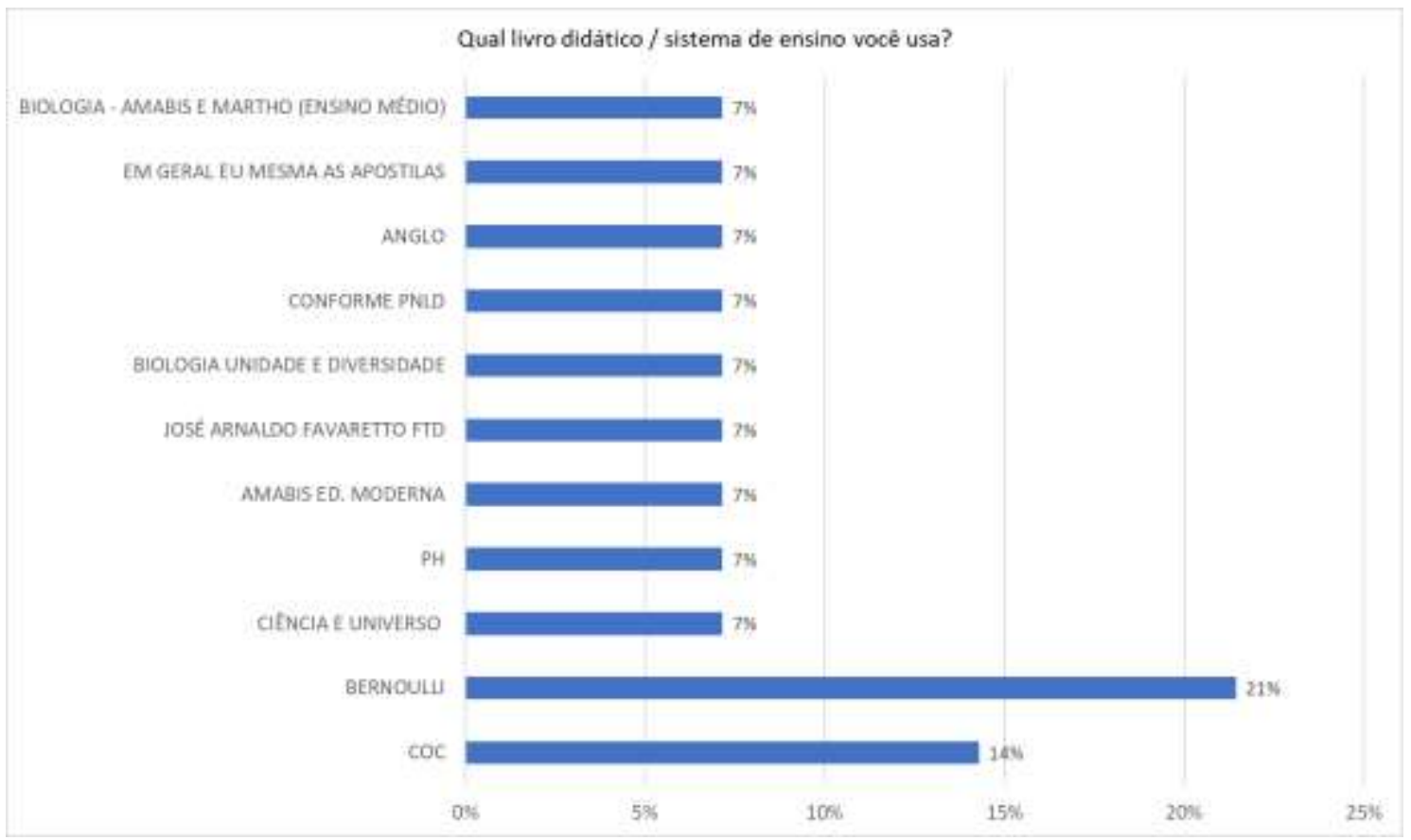

Fonte: Autores. 
Mesmo com essa grande variedade bibliográfica, o gráfico 3 mostra que oito $(58,9 \%)$ dos professores afirmaram que o conteúdo "pílula contraceptiva de emergência" não era mencionado ou que não se lembravam de tal tema nos livros didáticos ou sistemas de ensino utilizados em suas aulas.

Gráfico 3 - Menção à "pílula contraceptiva de emergência” no livro didático/sistema de ensino.
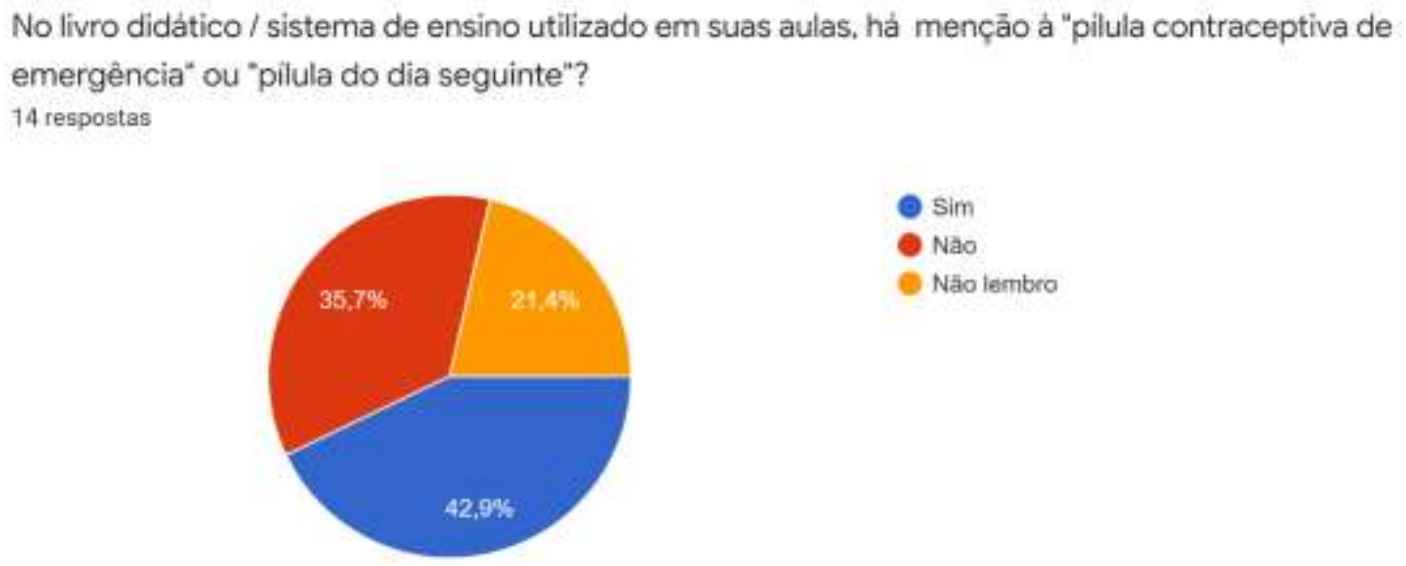

Fonte: Autores.

Apesar de tamanha relevância que a Educação Sexual assume de acordo com os Parâmetros Curriculares Nacionais, sendo tratada como um tema transversal (Brasil, 1997; 1998), vários materiais didáticos não incluem o tema $\mathrm{AE}$ em seus conteúdos. Essa não inclusão influencia os professores a não tratarem do assunto, mesmo sendo a $\mathrm{AE}$ popular entre os adolescentes.

Mesmo que algum tema relevante como esse não apareça no material didático, é de suma importância que o professor insira-o em suas aulas. O professor precisa de autonomia para selecionar os conteúdos que são essenciais e aqueles que são acessórios. E a partir dessa seleção, planejar e desenvolver estratégias para que seu aprendizado seja significativo.

$\mathrm{O}$ fato de três professores não lembrarem se a $\mathrm{AE}$ era mencionada nos materiais didáticos que trabalhavam (Gráfico 3), pode sugerir a pouca atenção dada ao tema. Também pode sugerir que é possível que o assunto apareça no material didático e o professor possa não abordá-lo por se sentir desconfortável ou por julgar não ser importante, o que somado a uma possível falta de capacitação do professor, faz com que o tema não seja sequer mencionado, quanto mais abordado de forma significativa.

Apesar da maioria de dez $(71,4 \%)$ dos professores crer que o tema "pílula contraceptiva de emergência" seja muito relevante (Gráfico 4) ou relevante (21,4\%), um dos 14 professores participantes da pesquisa considera o tema dispensável. Apesar de ser um número pequeno, chamou a atenção um profissional da área de Biologia julgar o tema dispensável e levantou questionamentos da razão de tal pensamento. Razões culturais, desmotivação ou ainda, a não obrigatoriedade dos PCN torna possível a existência de tal julgamento atualmente. 
Gráfico 4 - Opinião dos professores sobre a abordagem do tema "pílula contraceptiva de emergência" nas aulas.
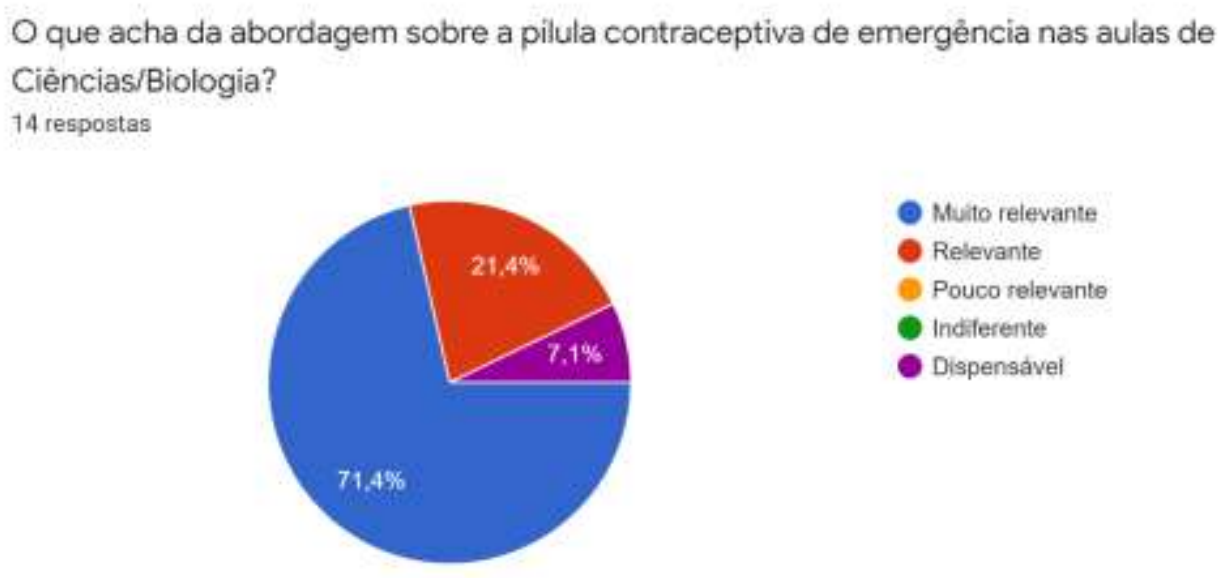

Muito relevante

Relevante

Pouco relevante

Indiferente

Dispensavei

Fonte: Autores.

Em relação à forma de abordar o tema em suas aulas, apenas quatro $(28,6 \%)$ dos professores demonstrou abordar o tópico de forma aprofundada, enquanto nove (64,3\%) afirmaram já ter explicado o funcionamento da pílula contraceptiva de emergência, porém de forma superficial e um (7,1\%) professor afirmou não ter explicado o tema em suas aulas (Gráfico 5). O número é significativo, uma vez que é um método contraceptivo muito utilizado pelos jovens e que ainda gera muitas dúvidas entre eles.

Gráfico 5 - Explicação do modo de ação da "pílula contraceptiva de emergência" nas aulas pelos professores.

Durante suas aulas, vocè já explicou o funcionamento da pilula contraceptiva de emergência? 14 respostas

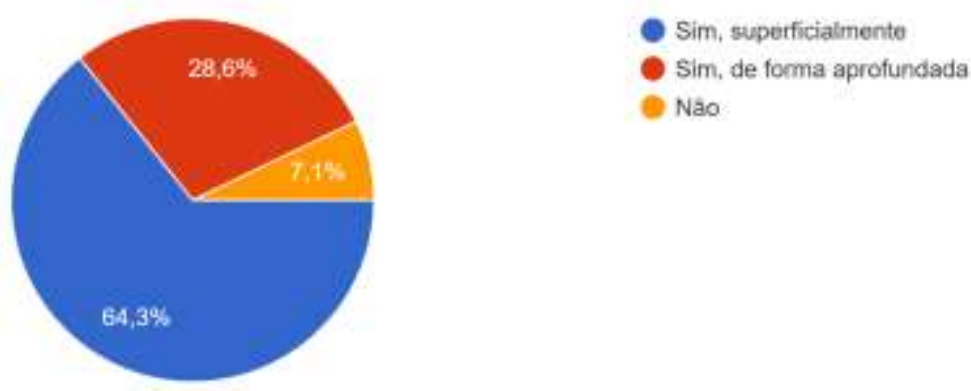

Fonte: Autores.

Apesar de já comprovado cientificamente que a pílula contraceptiva de emergência não possui efeito abortivo, seis $(42,9 \%)$ dos professores que responderam ao questionário online acreditavam que a pílula poderia ter algum efeito abortivo. Esses dados corroboram com o fato de parte significativa da população acreditar que a pílula contraceptiva de emergência é abortiva, pois apesar de existirem outros meios de comunicação que oferecem informações errôneas, espera-se que a escola passe o conhecimento baseado em fatos científicos e que, desta forma, o conhecimento chegue a todos.

Um aspecto que vale a pena ser discutido é o preparo dos professores para inserir temas considerados polêmicos em sala de aula, como a AE. Os professores, em sua maioria, também não tiveram esse preparo na educação básica e sequer no ensino superior, como afirma a pesquisa de Silva e Neto (2006). Portanto, por maior que seja o esforço do professor, torna-se 
difícil levar para a sala de aula algum assunto sem o devido preparo. O próprio documento introdutório dos PCN aponta que o professor deve estar preparado para abordagem do tema em questão através de discussão e leitura, possibilitando uma reflexão. (Brasil, 1998). Vale ressaltar que o despreparo produz, por vezes, condutas discriminatórias e pouco reflexivas, o que ajuda na imposição de mitos relativos à Educação Sexual. Ainda que esse seja um tema polêmico que envolve tabus, valores ou aspectos religiosos, o professor precisa se deter na cientificidade dos fatos, para poder esclarecer aos alunos de forma imparcial.

Nessa perspectiva, os professores foram questionados sobre as dificuldades encontradas na abordagem do tema "Pílula contraceptiva de emergência" em suas aulas. De acordo com o Quadro 1, o quantitativo de quatro professores não encontrou dificuldades ao abordar esse tema. Três professores citaram alguma palavra relacionada a "aborto" em suas respostas; dois deles demonstraram conhecimento sobre o método não ser abortivo, mas que a sociedade ou os próprios alunos o consideram: "alguns alunos são contra porque encaram como método de aborto" e "o fato desse recurso ser erroneamente taxado como abortivo por parte da sociedade e ser considerado tabu". Apenas um dos professores que relacionou sua dificuldade em abordar o assunto ao aborto, questionou se o método poderia ser abortivo: “aborto ou não?”, demonstrando, possivelmente, sua própria falta de conhecimento, como mostrado no gráfico anterior, e confirmando a incerteza da sociedade em relação à ação da pílula contraceptiva de emergência. Garcia (2017) relatou em sua pesquisa com 381 pessoas, que 64,2\% dos participantes afirmou não saber se a AE possuía efeito abortivo.

Quadro 1 - Dificuldades encontradas pelos professores durante as aulas.

\begin{tabular}{|c|c|}
\hline \multicolumn{2}{|c|}{ Cite, em poucas palavras, uma dificuldade encontrada durante a abordagem do tema "pílula contraceptiva } \\
de emergência":14 respostas
\end{tabular}

Fonte: Autores. 
Um professor abordou o fator "contraindicações" e a falta de conhecimento acerca do assunto, deixando, novamente, a suposição da sua falta de conhecimento e da necessidade de conhecer mais sobre o tema. Outro participante afirmou que sua dificuldade era o fato de "a já utilização da pílula contraceptiva de emergência por algumas alunas". De fato, essa é a realidade no Brasil, onde pesquisas apontam uma média de 27,8\% e 26,20\% de adolescentes fazem uso da AE. (Sousa et al, 2016)

Outros três professores participantes da pesquisa levantaram como dificuldade a "falta de liberdade para os estudantes debaterem temas relacionados ao sexo e à sexualidade na adolescência", "o preconceito que ainda perdura ao falar sobre tudo que seja relativo a questão do sexo" e os "mitos relacionados ao uso da pílula". Essas respostas refletem a realidade porque, de maneira geral, o tema sexualidade em sala de aula desperta, entre os adolescentes, medo, sentimentos de despreparo, vergonha, insegurança e falta de confiança e as ações dos profissionais acabam sendo orientadas pelos valores pessoais dos mesmos. (Célia \& Neto, 2020)

Um participante da pesquisa respondeu que "o entendimento de um método contraceptivo ineficaz que pode trazer danos ao corpo da mulher" como uma dificuldade para sua abordagem, deixando a suposição, mais uma vez, da falta de conhecimento dos alunos e da sociedade sobre o tema. Essa resposta, assim como a anterior só reflete, novamente, a necessidade de abordar esse assunto em sala de aula, pois se torna um ciclo no qual um professor despreparado aborda de forma superficial ou errônea o tema ou não o aborda e, assim, os alunos saem da escola sem uma aprendizagem significativa acerca do assunto, sem preparo para fazer uma reflexão madura e consistente e, desta forma, a sociedade como um todo continua acreditando e propagando mitos a respeito da anticoncepção de emergência.

Por último, um professor levantou a dificuldade da falta de receptividade dos alunos, quando afirmou que "difícil fazer o aluno entender que estamos ensinando para o bem dele". Essa resposta reforça a importância da utilização de metodologias ativas para que o aluno tenha outra visão do que aprende na escola. $\mathrm{O}$ adolescente tende a não valorizar a abordagem de caráter proibicionista ou baseada em conselhos e sermões como estratégia educativa.

Torna-se claro que o "sentido de prevenir" na pedagogia do controle, pautada na abordagem proibicionista, se distancia do "sentido de educar", qual seja, formar cidadãos críticos, autônomos e responsáveis por si mesmos. (Ronzani e Silveira, 2014)

Nessa perspectiva, os professores foram, finalmente, questionados sobre a utilização de metodologias de aprendizagem ativa. 100\% dos professores que participaram da pesquisa afirmaram utilizá-las em suas aulas. Entre essas metodologias, as mais utilizadas são "Sala de aula invertida" (citada por 10 professores), "Aprendizagem baseada em problemas", "Aprendizagem baseada em projetos", "Sequência didática" (todas citadas por 9 professores) e "Metodologia da Problematização" (citada por 8 professores) (Gráfico 6). Enquanto as metodologias "Peer Instruction" e "Jigsaw" são as menos utilizadas (citadas por apenas 2 professores). 
Gráfico 6 - Metodologias de aprendizagem ativas já utilizadas pelos professores.

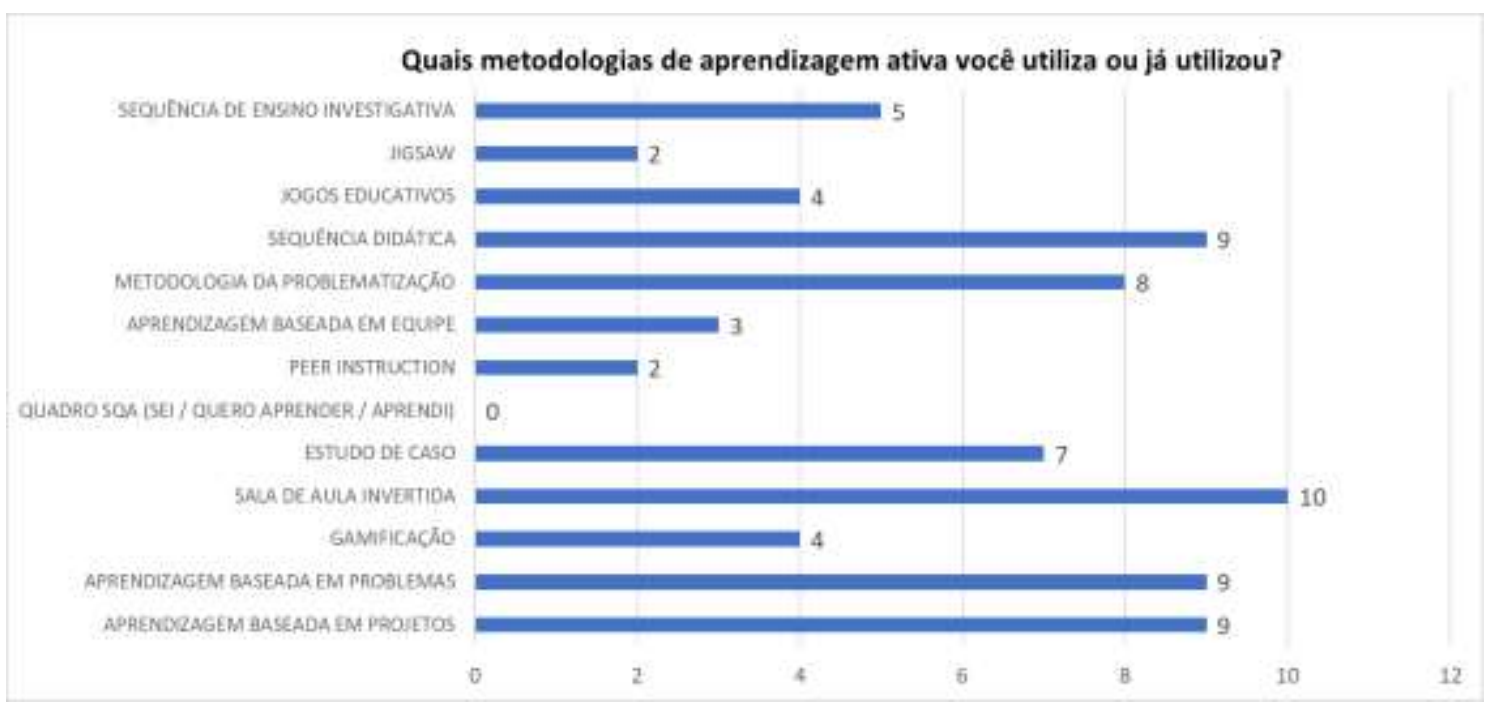

Fonte: Autores.

A utilização de metodologias de aprendizagem ativa por todos os participantes da pesquisa afirma a importância de utilizar metodologias ativas dentro de sala de aula, principalmente para temas relevantes como este a fim de que a aprendizagem seja significativa e os alunos possam ser capazes de aplicar esse conteúdo em suas vidas, tomando futuras decisões de forma consciente.

\section{Conclusão}

Este trabalho demonstrou a importância da ampliação do debate na escola e na sociedade sobre os métodos contraceptivos e, especialmente, sobre a pílula contraceptiva de emergência. Além disso, existe a necessidade de se aprofundar esse assunto entre os professores, pois os mesmos, apesar de considerar o tema relevante, o abordam superficialmente em suas aulas ou não o abordam. Muitos professores que lecionam a disciplina Biologia no Ensino Médio em Campos dos Goytacazes/RJ consideraram, erroneamente, a AE como um método abortivo. Além disso, relataram como as maiores dificuldades em abordar a AE, o fato do tema ainda ser um tabu e ser considerado abortivo. Também foi observado que alguns materiais didáticos não apresentam nenhuma abordagem sobre a AE. As aulas de educação sexual aprendidas nas escolas são muito restritas; geralmente é um tema tratado nas disciplinas de Ciências e Biologia, porém de forma muito rasa, focando apenas nas formas de reprodução ligadas ao corpo humano. É preciso urgência em aprofundar essa discussão na escola, tanto nos materiais didáticos quanto entre os professores, para ampliar o conhecimento dos alunos e da sociedade e reduzir os mitos e preconceitos relacionados ao tema. Sugere-se o aprofundamento do tema também nos cursos de preparação de professores, para que os docentes consigam tratar sobre esses temas tão delicados, mas tão importantes e necessários.

\section{Referências}

Almeida, R. A. A. S.; Corrêa, R. G. C. F. \& Rolim, I. L. T. P. (2017). Knowledge of adolescents regarding sexually transmitted infections and pregnancy. Revista Brasileira de Enfermagem, 70(5), 1033-9.

Alves, A. S. \& Lopes, M. H. B. M. (2008). Uso de métodos anticoncepcionais entre adolescentes universitários. Revista Brasileira de Enfermagem, 61(2), $170-7$.

Alves, T. A.; Falcão, L. S.; Souza, A. T.; Amaral, T. S.; Lima, S. P. \& Carvalho, T. B. (2016). Fisio Card Game: um jogo didático para o ensino da fisiologia na educação básica. Revista de Ensino de Bioquímica, 14(1), 99-120.

Braga, A. P. C. \& Souza (2016). Efeitos do uso da contracepção de emergência: Revisão de literatura. Centro Universitário de Brasília - Faculdade de Ciências da Educação em Saúde - Curso de Biomedicina. Brasília-DF. 
Research, Society and Development, v. 10, n. 2, e55910212768, 2021

(CC BY 4.0) | ISSN 2525-3409 | DOI: http://dx.doi.org/10.33448/rsd-v10i2.12768

Brasil. Ministério da Educação. (1997-1998). Parâmetros Curriculares Nacionais para o Ensino Médio (PCNEM). Brasília-DF.

Brasil. Ministério da Saúde. (2005). Anticoncepção de Emergência - Perguntas e Respostas para profissionais de saúde. Série Direitos Sexuais e Direitos Reprodutivos - Caderno n ${ }^{\circ}$ 3. Brasília-DF.

Brasil. Ministério da Saúde. (2010). Diretrizes Nacionais para a Atenção Integral à Saúde de Adolescentes e Jovens na Promoção, Proteção e Recuperação da Saúde. Brasília-DF.

Brasil. Ministério da Saúde. (2012). Protocolo para Utilização do Levonorgestrel. Brasília-DF.

Consorcio Latinoamericano de Anticoncepción de Emergencia (CLAE) Federación Latinoamericana de Sociedades de Obstetricia Y Ginecología (FLASOG). (2015). Pílulas anticoncepcionais de emergência - Orientações médicas e de prestação de serviços.

Garcia, S.; Santos, M. \& Pereira, O. R. (2017). Uso de Contraceptivos de Emergência Na Cidade de Aveiros: Perfil de Utilização e Conhecimentos. Congresso Nacional das Tecnologias da Saúde (CNTS). Editora: Instituto Politécnico de Bragança.

Gerhardt, T. E. \& Silveira, D. T. (2009). Métodos de Pesquisa. Editora UFRGS.

Gudwin, R. (2020). Aprendizagem Ativa | Ricardo Gudwin's Home Page. Unicamp.br.

Leite, L. M. \& Rotta, J. C. G. (2013). Digerindo a química biologicamente: uma proposta lúdica para o ensino de ciências a percepção de alunos do ensino médio. Universidade de Brasília. Brasília-DF.

Melo, N. R. et. al. (1997). Anticoncepção. Federação Brasileira das Sociedades de Ginecologia e Obstetrícia. Comissão Nacional Especializada de Planejamento Familiar.

Moreira, Marco Antonio. (2003). Pesquisa em ensino: aspectos metodológicos. Instituto de Física, UFRGS.

Nascimento, F. \& Soares, F. (2015). Uso indiscriminado de "pílulas do dia seguinte" por adolescentes. Seminário Internacional de Educação no MERCOSUL. Universidade de Cruz alta; UNICRUZ.

Pereira, A. S. et al (2018). Metodologia da pesquisa científica. UFSM.

Portela, Cidilena Guedes. (2015). Uso discriminado da pílula do dia seguinte. Rondônia. Faculdade de Educação e Meio Ambiente; FAEMA.

Ronzani, T. \& Silveira, P. (2014). Prevenção ao uso de álcool e outras drogas no contexto escolar. Editora UFJF.

Serra, Claudiana Batalha. (2017). Educação em sexualidade na escola: um projeto com adolescentes. Instituto Politécnico de Coimbra; ESTeSC.

Silva, M. R. B.; Silva, L. A. \& Maturana, H. C. A. (2015). Por que elas não usam? um estudo sobre a não adesão das adolescentes aos métodos contraceptivos e suas repercussões. Saúde em Redes, 1(4), 75-83.

Silva, R. C. P. \& Neto, J. M. (2006) Formação de professores e educadores para a abordagem da educação sexual na escola: o que mostram as pesquisas. Ciência e Educação, Bauru, 12(2), 185-197.

Sousa, S. R. G. R.; Franca, C.; Colares, V. \& Nóbrega, A. B. S. (2016). Conhecimento e uso da contracepção de emergência na adolescência. Adolesc. Saúde, Rio de Janeiro, 13(2), 167-173.

Viçosa, C. S. C. L. et. al. (2020). Saúde do adolescente e Educação Sexual na escola: tecituras a partir das perspectivas dos estudantes. Research, Society and Development, 9(6).

Vonk, A. C. R. P.; Bonan, C. \& Silva, K. S. (2013). Sexualidade, reprodução e saúde: experiências de adolescentes que vivem em município do interior de pequeno porte. Ciência \& Saúde Coletiva, 18(6), 1795-1807. 